\title{
Role of Healthy Food Daily Consumption on the Forming of the Breasts, Thighs, Buttocks for Getting Healthy, Sexy and Interesting Body
}

\section{Rosa Lelyana*}

Medical Doctor, Researcher, Lecturer of Medicine Faculty of Diponegoro University, Indonesia

*Corresponding Author: Rosa Lelyana, Medical Doctor, Researcher, Lecturer of Medicine Faculty of Diponegoro University, Indonesia.
Received: July 14, 2020

Published: August 08, 2020

(C) All rights are reserved by Rosa Lelyana.

\section{Abstract}

Introduction: A person's body shape is influenced by various factors. Many women who want a healthy body shape, sexy and attractive. One of the parameters of a woman's attractiveness is the shape and size of her breasts, thighs and buttocks. Unclear understanding the ways to get a healthy, beautiful and attractive body shape because of many factors that influence it. One of many factors is the food factor, but it is still unknown how food affects the formation of breasts, thighs and buttocks. Therefore, this paper aims to discuss the role of food in the formation of breasts, thighs and buttocks in women so that they look healthy, sexy and attractive.

Methods: Systematic Review.

Results: Consumption of healthy foods consists of carbohydrates, proteins, fats, vitamins, minerals and water. Consumption of healthy foods affects of someone body shape. Consumption of dairy food, yogurt, spicy favor, eggs, chicken breast, beef, flax seeds, whey protein, fatty fish, beans, legumes, soybeans, vegetables, vitamins and minerals will influence the formation of fat cells and muscle cells. In fact, exercise helps food activity in influencing the formation of cells and organs of the body.

Discussion: The breasts, thighs and buttocks are mostly composed of fat and supporting muscle tissue around the area of the organ. Body fat tissue is obtained from food consumption. Excessive consumption of food that is not used by the body will be stored as adipose tissue. Muscle tissue is formed from the consumption of various foods, especially those containing protein. Consumption of healthy food affects the formation of body cells or body cells forming naturally.

Conclusion: Consumption of healthy foods will affect the formation of body cells such as fat cells and muscle cells so that they will form healthy, sexy and attractive breasts, buttocks and thighs.

Keywords: Food; Healthy; Forming; Breasts; Thighs; Buttocks

\section{Introduction}

Breasts, thighs and buttocks are female organs that specifically store fat. When a woman experiences pregnancy and breastfeeding, the body part will grow in line with the greater energy requirements for the pregnancy and the baby being breastfed. The breasts, buttocks and thighs are a place of storage of fat which is a marker of a woman's fertility and a characteristic marker of a woman's body and is used as a sexual attraction [1]. The results of the study show that men and women prefer breasts with an average size or slightly above average [2]. The results of the study show the reality in today's society that the shape of the breasts, buttocks and thighs greatly affect the appearance. One of the factors that influence the formation of breasts, thighs and buttocks is food. Food is known to affect a person's body shape so it looks more beautiful and attractive. This study review aims to discuss the role of healthy food in influencing the formation of breasts, buttocks and thighs. 


\section{Methods}

Review study.

\section{Results and Discussion}

In women, mammary epithelium that invades mammary fat cells will cause epithelial proliferation, breast enlargement, and increased deposition of fat tissue. In men, this process is inhibited by increasing testosterone levels [3]. Buttocks are a male female body part consisting of fat and connective tissue [4]. Thigh area consisting of fat and muscle is an area of the body that needs attention because it is related to body health, where according to the results of previous studies, the average thigh circumference in men is $53.3 \pm$ $5.0 \mathrm{~cm}$ and $52.6 \pm 4.7 \mathrm{~cm}$ for women $(\mathrm{p}<0.001)$. Large or small size of the thigh circumference affects the risk of disease in a person's body. A smaller thigh circumference will affect an increased risk of various diseases than a large thigh circumference [5].

The study results show that girls in Chilean who don't consume yogurt (but more often consume mixed-dairy or artificially-flavored milk-based drinks and sweeteners) are associated with higher fibroglandular mamae volume and menarche age that is not late than girls who consume a lot of yogurt [6]. Dairy food consumption is related to fat consumption where excessive fat consumption is related to the risk of cancer [7]. Likewise, milk consumption is related to the presence of higher endogenous growth hormone and an increase in insulin-like growth factor (IGF) 11 I, and secretion of IGF-binding protein 3 in a person's body, thereby affecting the body's growth and development [8-12].

The body also needs to pay attention to the consumption of healthy foods that have benefits in preventing various diseases including cancer. Consumption of healthy foods requires a food composition that has anti-tumor activity so that it has the potential to reduce the number and development of tumors. Among foods that contain anti-tumor activity is spicy food. Spicy food is food that contains pepper and capsaicin where the food can activate the receptors of cells found in the digestive tract so that it has anti-tumor activity [13-16].

The body also needs to consume eggs (egg white and egg yolk) to further increase the stimulation of muscle protein synthesis so that it helps the formation of muscle cells rather than consumption of egg whites alone [17-19].

Another important food consumed for body formation is chicken breast where consumption of chicken breast accelerates the growth of muscle cells. However, stress conditions will also affect the body's metabolism and accelerated muscle growth $[17,18,20]$.

Dairy products like milk where milk content will affect skeletal muscle growth. Milk consumption is very important for the formation of muscle cells because when the body experiences skeletal muscle loss, it will disrupt daily mobility and activity [21]. In addition, skeletal muscle plays an important role as glycaemic control, so if skeletal muscle lost, the body will not be able to perform glycemic control function. Then, will associate with the risk of developing diabetes mellitus especially if due to the formation of disrupted muscle cells, the body will experience a lack of physical activity daily [22]. This is related to the explanation of why someone's smaller thigh size will affect the increased risk of developing the disease. Where the loss of skeletal muscle or disruption of the formation of muscle cells will reduce mobility and daily activities as well as the function of glycemic control, which is also disrupted thereby increasing the risk of developing Diabetes Mellitus.

Other foods that affect the formation of body muscles are foods that contain yogurt. Yogurt is a good food consumed because it is rich in protein. Likewise, food products that contain soy and flax seeds are also good for consumption because they contain phytoestrogens. Another good food consumed for body muscle development is whey protein which will help enlarge the formation of muscles in the buttocks area so that the buttocks size will be bigger $[17,23]$.

Other healthy foods that are good for consumption are fatty fish, greek yogurt, protein found in plants such as nuts, legumes and whole grains and seeds. Similarly, foods that are rich in collagen content such as fish, chicken and beef will help to increase muscle formation, especially if without the consumption of sugar and alcohol [18].

Milk-based protein will enlarge the muscles when consumed after exercise/sports, rather than the consumption of foods in the form of soy-based protein [24]. The results of other studies show that consumption of foods containing soy-based protein as much as $20 \mathrm{~g}$ and $40 \mathrm{~g}$ will not stimulate an increase in the speed of MPS (myofibrillar protein synthesis) during resting conditions in the elderly, unless accompanied by exercise/sports but with consumption of soy-based protein as much as $40 \mathrm{~g}$ and not for consumption of $20 \mathrm{~g}$. And will not help increase the speed of MPS if only consumed as much as $20 \mathrm{~g}$ of soy protein without doing exercise/ sports [25]. 
In addition, consumption of protein derived from vegetables and the content of vitamin B-6, vitamin B-12 and folate consumption will improve body function in the elderly in a study conducted in the Netherlands [26].

Other supporting evidence that food contributes to muscle growth is that exercise and vitamin D consumption and supplementation can improve muscle strength in the elderly [27].

Example, in sarcopenia conditions where muscle strength and function, nutritional status, body composition and quality of life and muscle mass and physical exercise levels are lower than in non-sarcopenia conditions, energy intake, protein, also vitamin B-12 and Mg, phosphorus and Se will be lower in the condition of sarcopenia rather than food consumption of someone with a non sarcopenia condition. Likewise, vitamin B12 levels will be 15\% lower in sarcopenia than non sarcopenia condition, and other nutrient levels will be lower in sarcopenia than non sarcopenia [28].

Milk-based protein will enlarge the muscles when consumed after exercise/sports, rather than the consumption of foods in the form of soy-based protein [24]. The results of other studies show that consumption of foods containing soy-based protein as much as $20 \mathrm{~g}$ and $40 \mathrm{~g}$ will not stimulate an increase in the speed of MPS (myofibrillar protein synthesis) at rest conditions in the elderly, unless accompanied by exercise/sports but with consumption of soy-based protein as much as $40 \mathrm{~g}$ and not for consumption of $20 \mathrm{~g}$. And will not help increase the speed of MPS if only consumed as much as $20 \mathrm{~g}$ of soy protein without doing exercise/sports [25].

In addition, consumption of protein derived from vegetables and the content of vitamin B-6, vitamin B-12 and folate consumption will improve body function in the elderly in a study conducted in the Netherlands [26].

Other supporting evidence that food contributes to muscle growth is that exercise/consumption and vitamin D consumption and supplementation can improve muscle strength in the elderly [27].

Example, in sarcopenia conditions where muscle strength and function, nutritional status, body composition and quality of life and muscle mass and physical exercise levels are lower than in non-sarcopenia conditions, energy intake, protein, also vitamin B-12 and Mg, phosphorus and Se will be lower in the condition of sarcopenia rather than food consumption of someone with a non sarcopenia condition. Likewise, vitamin B12 levels will be 15\% lower in sarcopenia than non sarcopenia and other nutrient levels will be lower in sarcopenia than non sarcopenia [28].

All food consumption will affect the formation of body cells. The average speed of protein synthesis from basal fractional muscle, tendon, bone, cartilage, ligament and menisci ranges between 0.02 and $0.13 \%$ per hour in vivo in humans [29]. The portion of myofibrillar protein represents up to $85 \%$ of muscle fiber volume [30,31].

The formation of body cells will affect the shape and size of breasts, buttocks and thighs. It is well known that thermogenic fat cells consist of 2 cells namely termed brown and beige adipocytes which will cause an increase or decrease in beige fat activity along with the physiological consequences of the body [32]. It is also known that the breasts, thighs and buttocks consist of fat cells/adipose cells [1], where adipose tissue grows through 2 mechanisms namely hypertrophy - where each fat cell will increase in volume and through the mechanism of hyperplasia, where new cells will be produced from stem cells/stem cells so that more new cells are added.

The formation of body cells is influenced by the consumption of food such as consumption of fish and mammals will affect the same molecular pathways in regulating the expansion of adipose tissue so that consumption of fish and mammals is very important for the formation of fat cells because it is likely to pass through these mechanisms in regulating the expansion of adipose tissue [33].

The results of a study show that the most important thing about the shape and size of a person's body is the assessment of the importance of breast size that seems to vary from time to time and according to the sex evaluator in a study [34]. That is, the assessment of the attractiveness of women's body size (for example breasts) varies according to the time of the study and varies according to the sex of the study subject at the time of the study. Likewise, exercise influences the formation of muscle cells $[35,36]$ so that it will affect the formation and size of a person's body.

\section{Conclusion}

The formation of a woman's body is influenced by various factors including food. Food will affect the growth of muscle cells and fat cells so as to form a person's breasts, buttocks and thighs.

Citation: Rosa Lelyana. "Role of Healthy Food Daily Consumption on the Forming of the Breasts, Thighs, Buttocks for Getting Healthy, Sexy and Interesting Body". Acta Scientific Women's Health 2.9 (2020): 03-07. 


\section{Acknowledgment}

Thanks to my colleague Adam MSA and Jack B, who inspire this manuscript for increasing our greater knowledge related to perform of healthy body.

\section{Conflict of Interest}

No conflict of interest.

\section{Bibliography}

1. Ran Arieli. "Breasts, Buttocks, And The Camel Hump". Israel Journal of Zoology 50 (2004): 87-91.

2. Krzysztof Kościński. "Breast firmness is of greater importance for women's attractiveness than breast size". American Journal of Human Biology 31.5 (2019).

3. Alejandro Aranda Gutierrez and Hector M Diaz-Perez. Histology, Mammary Glands. 2020, StatPearls Publishing LLC (2020).

4. Sharon Eve Sonenblum., et al. "3D Anatomy and Deformation of the Seated Buttocks". Journal of Tissue Viability 24.2 (2015): 51-61.

5. Jie Shi., et al. "Large thigh circumference is associated with lower blood pressure in overweight and obese individuals: a community-based study". Endocrine Connections 9.4 (2020): 271-278.

6. Audrey J Gaskins., et al. "Dairy intake in relation to breast and pubertal development in Chilean girls". The American Journal of Clinical Nutrition 105.5 (2017): 1166-1175.

7. Ranganathan R., et al. "The nutritional impact of dairy product consumption on dietary intakes of adults (1995-1996): the Bogalusa Heart Study". Journal of the American Dietetic Association 105 (2005): 1391-1400.

8. Holmes MD., et al. "Dietary correlates of plasma insulin-like growth factor I and insulin-like growth factor binding protein 3 concentrations". Cancer Epidemiology, Biomarkers and Prevention 11 (2002): 852-861.

9. Ma J., et al. "Milk intake, circulating levels of insulin-like growth factor-I, and risk of colorectal cancer in men". Journal of the National Cancer Institute 93 (2001): 1330-1336.

10. Hoppe C., et al. "High intakes of skimmed milk, but not meat, increase serum IGF-I and IGFBP-3 in eight-year-old boys". European Journal of Clinical Nutrition 58 (2004): 1211-1216.

11. Rich-Edwards JW., et al. "Milk consumption and the prepubertal somatotropic axis". Nutrition Journal 6 (2007): 28.
12. Boyd NF., et al. "Mammographic density and the risk and detection of breast cancer". The New England Journal of Medicine 356 (2007): 227-236.

13. Mustafa Chopan., et al. "The Association of Hot Red Chili Pepper Consumption and Mortality: A Large Population-Based Cohort Study" (2017).

14. Aggarwal BB., et al. "Molecular targets of nutraceuticals derived from dietary spices: potential role in suppression of inflammation and tumorigenesis". Experimental Biology and Medicine (Maywood, NJ) 234.8 (2009): 825-849.

15. Kaufui V Wong. "The Health Benefits of Hot, Spicy Foods, with the Use of Chili Peppers". EC Nutrition 9.2 (2017): 116-120.

16. Mark F McCarty., et al. "Capsaicin may have important potential for promoting vascular and metabolic health". Open Heart 2.1 (2015): e000262.

17. Mia Lopez MS. "7 Foods and Supplements That Will Make Your Butt Bigger". Fitmozine Health and Fitness Magazine (2020).

18. Lindsay Tigar. Looking to Build a Stronger Butt? Here Are 5 Foods to Eat (and 2 to Avoid). Livestrong.com.

19. Stephan van Vliet., et al. "Consumption of whole eggs promotes greater stimulation of postexercise muscle protein synthesis than consumption of isonitrogenous amounts of egg whites in young men". The American Journal of Clinical Nutrition 106.6 (2017): 1401-1412.

20. Enrico Zanetti., et al. "A note on protein expression changes in chicken breast muscle in response to time in transit before slaughtering". Proteome Science 11 (2013): 34.

21. Robin A McGregor and Sally D Poppitt. "Milk protein for improved metabolic health: a review of the evidence". Nutrition and Metabolism (Lond) 10 (2013): 46.

22. Kelley DE., et al. "Skeletal muscle fatty acid metabolism in association with insulin resistance, obesity, and weight loss". American Journal of Physiology 277 (1999): E1130-1141.

23. Juha J Hulmi., et al. "The effects of whey protein with or without carbohydrates on resistance training adaptations". Journal of the International Society of Sports Nutrition 12 (2015): 48.

24. Sarah B Wilkinson., et al. "Consumption of Fluid Skim Milk Promotes Greater Muscle Protein Accretion After Resistance Exercise Than Does Consumption of an Isonitrogenous and Isoenergetic Soy-Protein Beverage". The American Journal of Clinical Nutrition 85.4 (2007): 1031-1040. 
25. Yifan Yang., et al. "Myofibrillar protein synthesis following ingestion of soy protein isolate at rest and after resistance exercise in elderly men". Nutrition and Metabolism (Lond). 9 (2012): 57.

26. Pariya Behrouzi., et al. "Dietary Intakes of Vegetable Protein, Folate, and Vitamins B-6 and B-12 Are Partially Correlated with Physical Functioning of Dutch Older Adults Using Copula Graphical Models". Journal of Nutrition 150.3 (2013): 634-643.

27. Anneka Elizabeth Antoniak and Carolyn A Greig. "The Effect of Combined Resistance Exercise Training and Vitamin D 3 Supplementation on Musculoskeletal Health and Function in Older Adults: A Systematic Review and Meta-Analysis". BMJ Open 7.7 (2017): e014619.

28. Sjors Verlaan., et al. "Nutritional Status, Body Composition, and Quality of Life in Community-Dwelling Sarcopenic and Non-Sarcopenic Older Adults: A Case-Control Study". Clinical Nutrition 36.1 (2017): 267-274.

29. Joey SJ Smeets., et al. "Protein synthesis rates of muscle, tendon, ligament, cartilage, and bone tissue in vivo in humans". PLoS One 14.11 (2019): e0224745.

30. Wladimir Bocca Vieira de Rezende Pinto., et al. "Normal muscle structure, growth, development, and regeneration". Current Reviews in Musculoskeletal Medicine (2015): 176-181.

31. Favier FB., et al. "Cellular and molecular events controlling skeletal muscle mass in response to altered use". Pflügers Archiv: European Journal of Physiology 456.3 (2018): 587-600.

32. Paul Cohena and Bruce M Spiegelman. "Cell biology of fat storage”. Molecular Biology of the Cell 27.16 (2016): 2523-2527.

33. Kathryn Knight. "The biology of fat". Journal of Experimental Biology 221 (2018): jeb178020.

34. Laura Buggio., et al. "“You Are So beautiful”*: Behind Women's Attractiveness Towards the Biology of Reproduction: A Narrative Review". Gynecological Endocrinology 28.10 (2012): 753757.

35. Craig BW., et al. "Adaptation of fat cells to exercise: response of glucose uptake and oxidation to insulin". Journal of Applied Physiology: Respiratory, Environmental and Exercise Physiology 51 (1981): 1500-1506.

36. Pablo Vidal and Kristin I Stanford. "Exercise-Induced Adaptations to Adipose Tissue Thermogenesis". Frontiers in Endocrinology (Lausanne) 11 (2020): 270.

\section{Assets from publication with us}

- Prompt Acknowledgement after receiving the article

- Thorough Double blinded peer review

- Rapid Publication

- Issue of Publication Certificate

- High visibility of your Published work

Website: www.actascientific.com/

Submit Article: www.actascientific.com/submission.php Email us: editor@actascientific.com

Contact us: +919182824667 